\title{
P08-04. The role of class I HLA-B and HLA-Cw in disease progression and maternal-infant HIV-I transmission in a South African population
}

\author{
M Paximadis*1, G Minevich², R Winchester ${ }^{2}$, DB Schramm6, GE Gray33, \\ GG Sherman ${ }^{4}$, AH Coovadia ${ }^{5}$, L Kuhn ${ }^{2}$ and CT Tiemessen ${ }^{6}$
}

Address: ${ }^{1}$ AIDS Virus Research Unit/Cell Biology, National Institute for Communicable Diseases, Johannesburg, South Africa, ${ }^{2}$ Columbia University, New York, USA, ${ }^{3}$ Chris Hani Baragwanath Hospital, Soweto, South Africa, ${ }^{4}$ National Health Laboratory Services, Johannesburg, South Africa, ${ }^{5}$ Coronation Women and Children Hospital, Johannesburg, South Africa and ${ }^{6}$ National Institute for Communicable Diseases and Wits University, Johannesburg, South Africa

* Corresponding author

from AIDS Vaccine 2009

Paris, France. 19-22 October 2009

Published: 22 October 2009

Retrovirology 2009, 6(Suppl 3):PII2 doi:I0.I I86/I742-4690-6-S3-PII 2

This abstract is available from: http://www.retrovirology.com/content/6/S3/PII2

(c) 2009 Paximadis et al; licensee BioMed Central Ltd.

\section{Background}

Human leukocyte antigens play an integral role in the cytotoxic T-cell pathway and serve as ligands for natural killer cell receptors. We have investigated the role of two HLA class I genes on disease progression and maternalinfant HIV-1 transmission using 222 South African mother-infant pairs recruited as part of a mother-to-infant HIV-1 transmission study.

\section{Methods}

High resolution genotyping of HLA class I B and Cw loci was performed using a sequence-based typing strategy and alleles were collapsed to a four-digit assignment for purpose of analysis.

\section{Results}

B*5802 and $\mathrm{Cw}^{*} 0602$ were significantly associated with high viral load $(\mathrm{VL})(\mathrm{P}=0.038$ and $\mathrm{P}=0.017$ respectively $)$ and low CD4 count $(\mathrm{P}<0.001$ and $\mathrm{P}=0.005$ respectively). These two alleles are in linkage disequilibrium ( $D^{\prime}$ $=1.00 ; \mathrm{P}<0.001)$ and the most prevalent haplotype amongst Black South Africans ( $\mathrm{f}=9.94 \%)$. The B*5802$\mathrm{Cw}^{*} 0602$ haplotype was also significantly associated with low $C D 4$ count $(P=0.001)$ and showed a trend with high VL $(P=0.073)$. Furthermore, $B * 4501$ showed a trend with high VL $(P=0.086)$ and low CD4 count $(P=0.062)$.
$\mathrm{B}^{*} 4201$ was significantly associated with low VL $(\mathrm{P}=$ 0.045 ) and another prevalent haplotype, $B^{*} 4201$ $\mathrm{CW}^{*} 1701(\mathrm{f}=9.65 \%)$, was significantly associated with low VL $(\mathrm{P}=0.049)$. The $\mathrm{Cw}$ allotype groups $(\mathrm{C} 1 \& \mathrm{C} 2)$ showed no significant association with markers of disease severity, whereas, contrary to other studies, Bw4/Bw4 homozygosity was significantly associated with high VL ( $P$ $=0.038)$ and low $\mathrm{CD} 4$ count $(\mathrm{P}=0.015) . \mathrm{B}^{*} 0801$ showed a trend $(P=0.064)$ of lower representation amongst infected infants compared to exposed uninfected infants. Transmitting mothers had significantly higher representation of $\mathrm{B}^{*} 1402(\mathrm{P}=0.034)$ and a trend of lower representation of $\mathrm{B}^{*} 4201 \quad(\mathrm{P}=0.082)$ compared to nontransmitting mothers. No $\mathrm{Cw}^{*}$ alleles or allotype groups showed significant association with HIV-1 transmission.

\section{Conclusion}

This study highlights the different roles played by HLA in disease progression and maternal-infant HIV-1 transmission and also serves as a basis for future work that will study the role of KIR-HLA in the same contexts. 